\title{
Breast diseases during pregnancy and lactation
}

\author{
Ji Hoon Yu', Min Jeong Kim², Hyonil Cho ${ }^{3}$, Hyun Ju Liư ${ }^{4}$, Sei-Jun Han ${ }^{4}$, Tae-Gyu Ahn ${ }^{4}$ \\ Department of Obstetrics and Gynecology, ${ }^{1}$ Miz Womens's Hospital, Daejeon; ${ }^{2}$ Bucheon St. Mary's Hospital, The Catholic University College of \\ Medicine, Bucheon; ${ }^{3}$ Incheon Seoul Women's Hospital, Incheon; ${ }^{4}$ Chosun University College of Medicine, Gwangju, Korea
}

Breast is a typical female sexual physiologic organ that is influenced by steroid hormone from menarche until menopause. Therefore various diseases can be developed by continuous action of estrogen and progesterone. Breast diseases are mainly categorized as benign and malignant. It is very important to distinguish the malignancy from breast diseases. However, it is very difficult to diagnose malignancy in pregnant and lactating women even though the same breast diseases took place. Therefore, we will review breast diseases such as breast carcinoma during pregnancy and lactation.

Keywords: Breast disease; Pregnancy; Lactation

\section{Introduction}

During pregnancy and lactation, a woman's breasts face several physiological changes. These changes can be attributed to various hormones, which may also cause vascular hyperplasia and hyperplastic lobules [1]. Such changes may hinder the interpretation of physical and medical imaging examinations of the breasts. It is important to note that most breast lesions that are diagnosed during pregnancy and lactation are benign; however, the different diagnosis of breast cancer is challenging during these periods. Therefore, the aim of this article was to review the changes occurring in the breast, which are related to pregnancy and lactation, and to identify methods for the different diagnosis and treatment of breast disease.

\section{Breast changes during pregnancy and lactation}

Breast begins to change under the influence of estrogen, progesterone, and prolactin from the mid-term in the first trimester of pregnancy. Particularly, by the influence of estrogen the blood vessels show remarkable growth, and lobules are proliferated. For the meantime, fibrolipoma substrate decreases, blood flow increases, and infiltration of mononuclear cell are often accompanied. During the second and the third period of pregnancy, the proliferation of lobules and the decrease in the substrate become more apparent. Normally, due to progester- one, cell proliferation in the unit of lobule appears apparently, and due to estrogen, the ductal proliferation comes to be much intense. Under the influence of the hormones prolactin and oxytoxin (secreted by the posterior pituitary gland), during late pregnancy, the alveolar cells produce early breast milk called colostrum by taking up nutrients from the blood. Foremilk and hindmilk, whose compositions are different from that of colostrum, are subsequently produced with the help of the hormone progesterone (lactogenesis I). In a period of lactation, due to drastic reduction of progesterone, prolactin levels increase. Shape of myoepithelial cell becomes much thinner and flatter, and along with insulin, thyroid hormone and other metabolic hormones, the myoepithelial cell synthesizes the basic nutrients of breast milk-fat, lactose, and protein (lactogenesis II). During a period of lactation, breast displays

Received: 2013.3.13. Revised: 2013.4.15. Accepted: 2013.4.17.

Corresponding author: Tae-Gyu Ahn

Department of Obstetrics and Gynecology, Chosun University College of Medicine, 365 Pilmun-daero, Dong-gu, Gwangju 501-717, Korea

Tel: +82-62-220-3690 Fax: +82-70-7545-4871

E-mail: ogatg@chosun.ac.kr

Articles published in Obstet Gynecol Sci are open-access, distributed under the terms of the Creative Commons Attribution Non-Commercial License (http://creativecommons. org/licenses/by-nc/3.0/) which permits unrestricted non-commercial use, distribution, and reproduction in any medium, provided the original work is properly cited.

Copyright (c) 2013 Korean Society of Obstetrics and Gynecology 


\title{
Obstetrics \& Gynecology Science
}

\author{
Vol. 56, No. 3, 2013
}
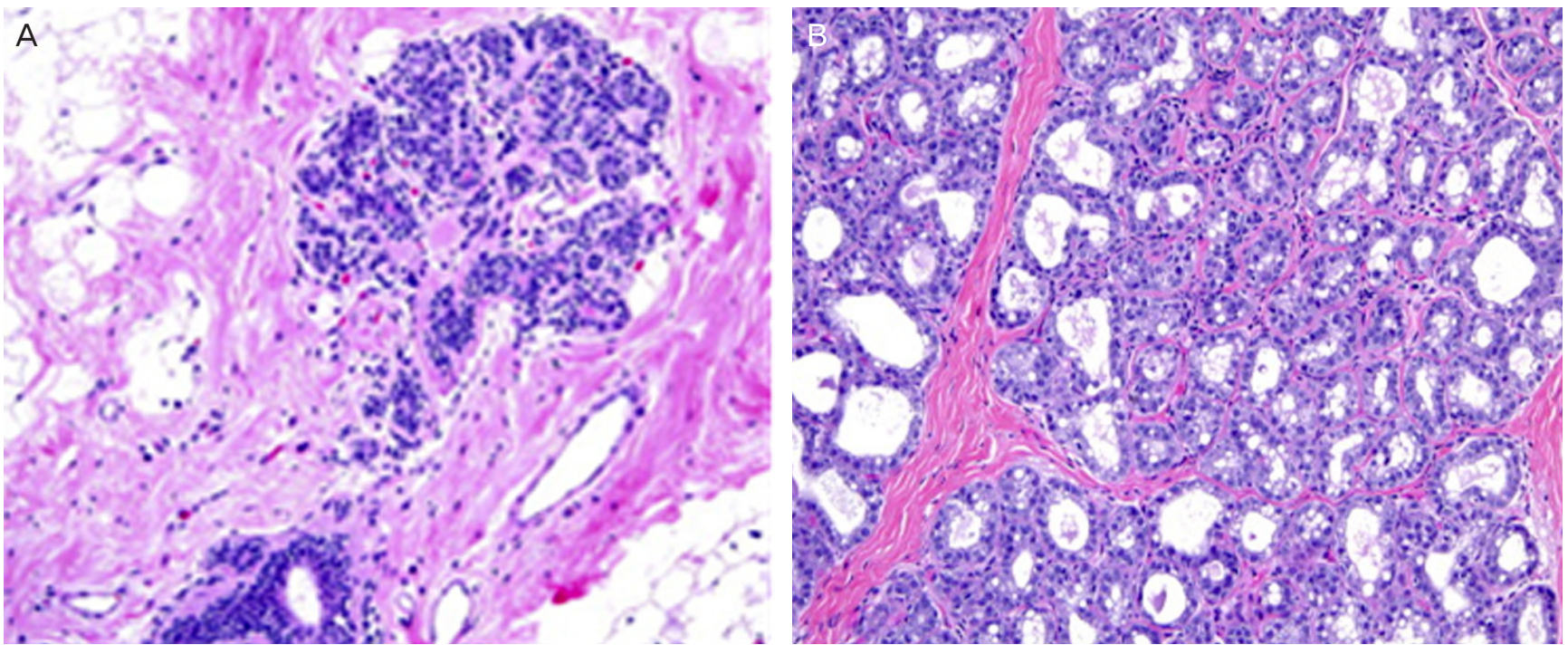

Fig. 1. Changes of breast tissue during lactation. (A) Terminal duct-lobular unit in non-pregnancy $(H \& E, \times 200)$. (B) Dilated lobular acini with vacuoles and secretions can be seen during lactation $(H \& E, \times 200)$.
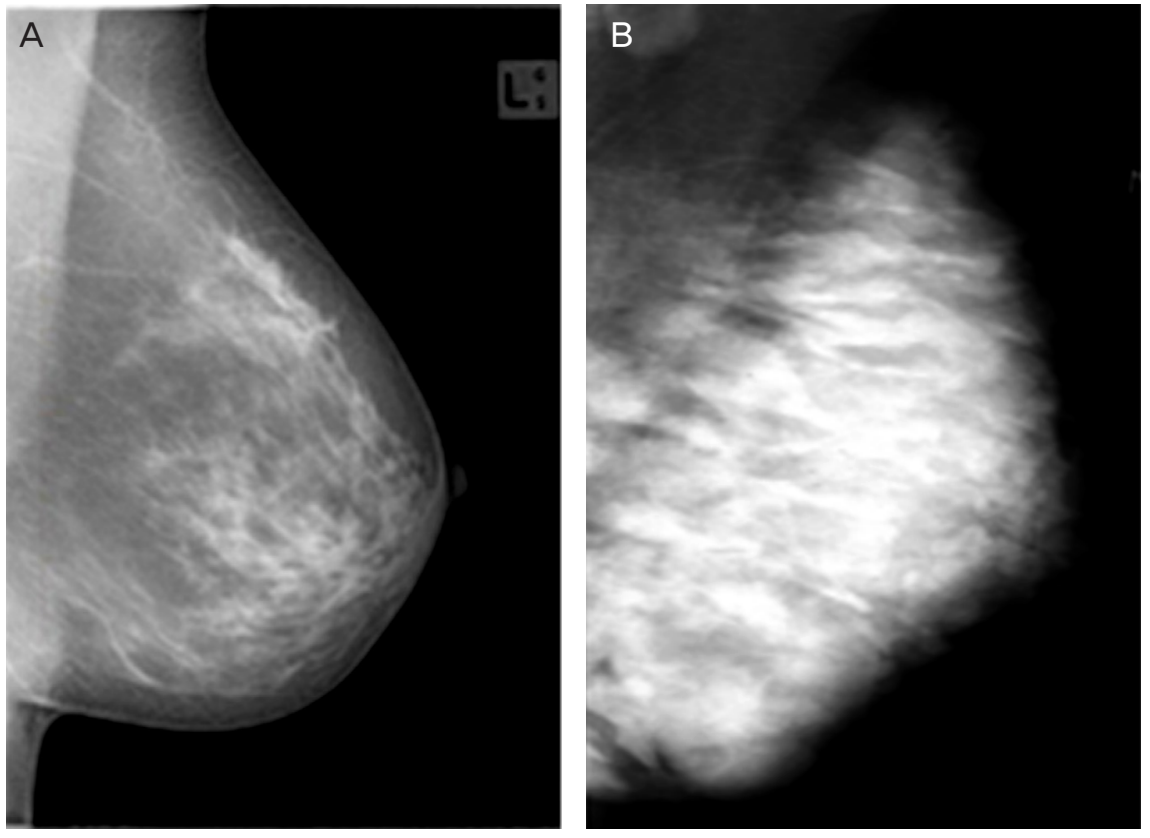

Fig. 2. Mammographic changes during lactation. (A) Type 2 American College of Radiology classification shows before pregnancy. (B) Mammogram during lactation shows a marked diffuse increase in density.

the lobular expansion as well as the accumulation of ductal secretion (Fig. 1). The breast milk is secreted by oxytocin and neuroendocrine interactions. To producing of breastfeeding constantly being generated during a period of lactation, a certain amount of oxytocin from the posterior pituitary needs to secrete by stimulating that comes from sucking (lactogenesis III) [2-6].

It takes three months after discontinuation of breast-feeding in order to pre-pregnancy state, and during this process pronounced atrophy of lobules is detected [3].

\section{Imaging and biopsy during pregnancy and lactation}

In this period, it is very difficult to distinguish between tumor and normal breast by clinical examination or imaging test. Since the breasts continue to grow and feel firm and nodular during pregnancy, it is possible that a tumor mass may appear as normal tissue during this period. Furthermore, as the breast increases its size, the tumor mass may be located deeper, making it more difficult to identify via palpation. 


\section{Obstetrics \& Gynecology Science}

Ji Hoon Yu, et al. Breast diseases in pregnancy \& lactation

\section{Mammography}

The physiological changes as stated above proliferates the breast parenchyma so that it increases the size, and increases the density of cells, blood vessels, or amount of moisture, therefore, the mammographic parenchymal density increase and diffuse (Fig. 2). Especially, during the lactation period, breast parenchymal density is further increased so that expansion of the lactic duct seems to be nodular and hyperdensity appearance by breast milk filling nipples. Therefore, in pregnant and lactating women, it is difficult to diagnose a tumor by mammography because of the architectural distortion and asymmetric density of the tumor. In such cases, ultrasonography is a more suitable diagnostic procedure than mammogra-

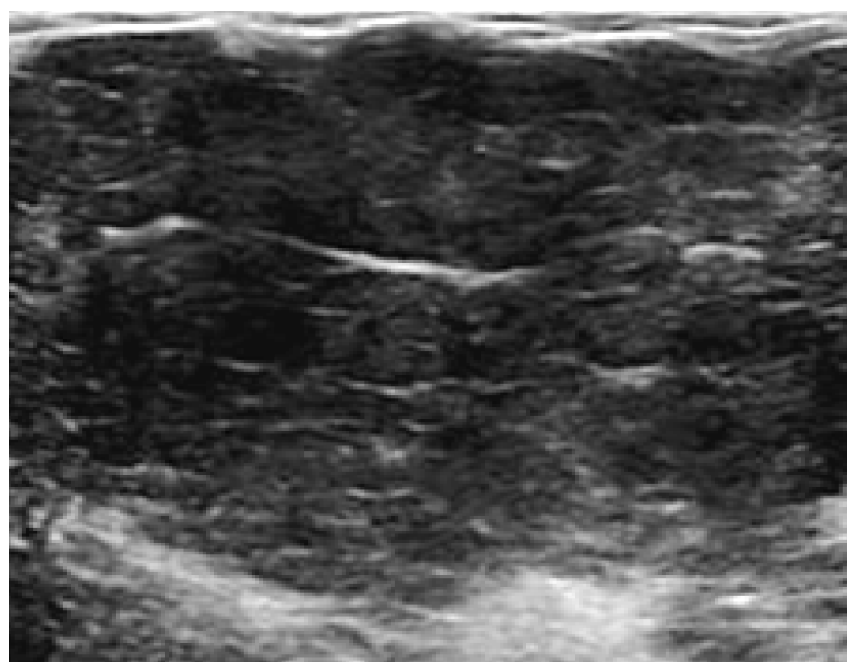

Fig. 3. Typical ultrasonographic feature during pregnancy shows diffuse enlargement of the non-fatty glandular component and global hypoechogenicity. phy. If a biopsy is indicated by ultrasonography, further mammography must be performed to identify the range of lesions, including microcalcification lesions [7-12]. It is thought that fetal abnormalities, which may occur due to radiation during pregnancy, would appear in case of more than $0.05 \mathrm{~Gy}$. Yet, the radiation that fetus can receive through the mammography introduced in 4 times, is very small as $0.004 \mathrm{~Gy}$, even if one does not wear lead aprons [13-15]. However, except special cases, it is recommended not conduct radiation tests during the first quarter of pregnancy.

\section{Breast ultrasonography}

One of the characteristics of breast ultrasonography conducted during pregnancy is that nonfatty fibroglandular tissue with diffuse feature becomes larger, as showing hypoechogenicity (Fig. 3). The other is that during a period of lactation, the nonfatty fibroglandular tissue displays hyperechogenicity, and both vascular tissue and vascular characteristic increase (Fig. 4) [7-11]. Ultrasonic waves can be used as the most dependable medical imaging examination to diagnose pregnancy and breast diseases that may appear during lactation period. In case of malignant breast lumps, ultrasonic represents its higher sensitivity against the lumps, rather than mammography $[8,9]$. It is known that pregnancy-associated breast cancer (PABC) occupies approximately $3 \%$ of all breast cancers. About $90 \%$ of PABC show lumps that are possible to be easily diagnosed by ultrasonic.

\section{Magnetic resonance imaging}

It is not recommended to use magnetic resonance imaging (MRI) as a general inspection for the diagnosis and treatment
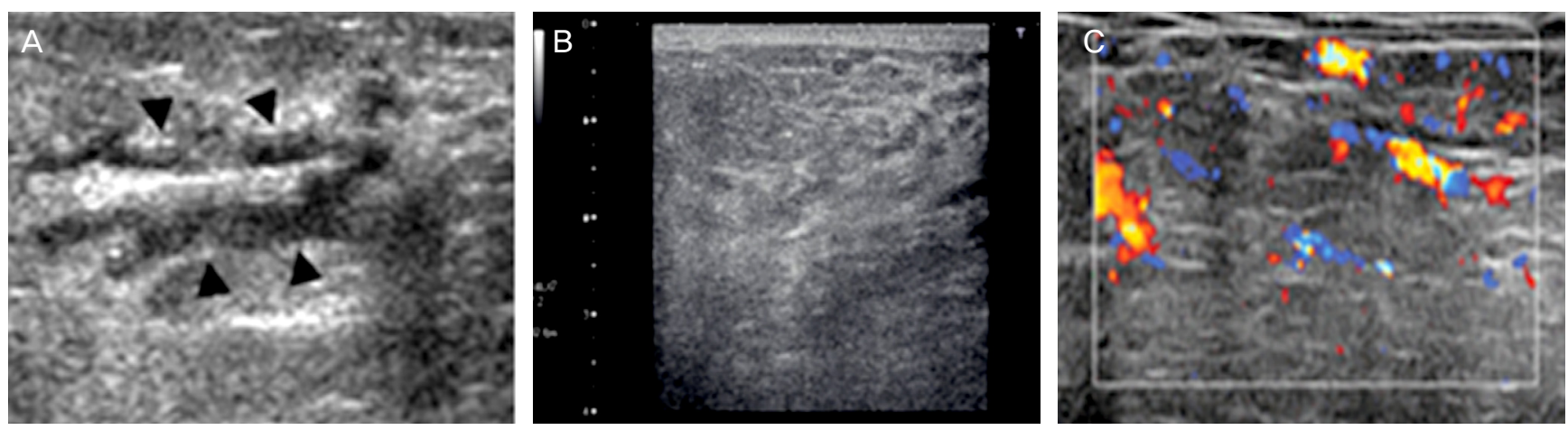

Fig. 4. Ultrasonographic changes during lactation. (A) Ultrasound (US) image shows irregular margined, hypoechoic dilated duct (black arrowhead). (B) US image reveals diffuse enlargement of the glandular component with diffuse hyperechogenicity. (C) Color Doppler US image reveals increased vascularity. 


\title{
Obstetrics \& Gynecology Science
}

\author{
Vol. 56, No. 3, 2013
}

of breast disease during pregnancy. According to American College of Radiology, in terms of diagnosis of breast diseases during pregnancy, MRI should only be used in cases that it would be regarded to have obvious benefits. It is also said that except special cases, contrast media should not be used [16]. However, in recent studies, it was reported that contrast media would not be closely related to foetal abnormalities $[17,18]$.

European Committee on Radiation Risk reported that gadolinium based contrast could be safely utilized during pregnancy, because it would be less absorbed into placenta and also, it would be rapidly excreted to kidney [19].

For MRI using gadolinium based contrast during a period of lactation makes less excretion to breast milk, it is known to be safe relatively $[18,19]$.

\section{Cytologic examination}

Since the mammary epithelial cells undergo several cellular morphological changes during pregnancy and lactation, a false-positive result may be obtained during the diagnosis of breast cancer. Therefore, the results of these diagnostic procedures must be carefully interpreted. A core biopsy examination of the suspected malignant lesion must be conducted and interpreted by a skilled pathologist $[20,21]$.

\section{Core biopsy}

Core biopsy, most appropriate method of tissue diagnosis in pregnancy and lactation period, is safe and economical (costeffective). The process of breast milk production is characterized by increased blood flow to the breast, which increases the risk of bleeding, and expansion of the milk ducts increases the risk of infection, which can cause a milk fistula because breast milk is generated in this stage. Milk fistula is known to occur more in central than in peripheral. Thus feeding temporarily suspend before aseptic surgery and a biopsy, biopsy is in the correct location and after the procedure, hemostasis using compresses or ice packs will help [22].

\section{Breast disease related to pregnancy, lactation period}

\section{Benign breast disease associated with physiological change}

1) Gestational and secretory hyperplasia

Microcalcification can be the result due to gestational hyperplasia associated with pregnancy and secretory hyperplasia associated with breast-feeding in mammography. This calcification looks mostly round and focal or diffuse distribution, but rarely shows a irregular, linear distribution, branching pattern. Round and small punctate calcifications represent lobular acinar proliferation and linear distribution represents the growth of the cannulated (Fig. 5) [23-25].

\section{2) Spontaneous bloody nipple discharge}

Bloody nipple discharge does not occur commonly in pregnancy or in a period of lactation. However, it can be cause by even small stimuli because the blood flow in breast increases rapidly and the change of epithelial cells gets even worst in 3rd trimester of pregnancy. Slight bloody nipple discharge can be seen from approximately $20 \%$ of nipple discharge during pregnancy and $15 \%$ of a period of lactation [26]. This phenomenon mostly stops as the lactate feeding begins, but also
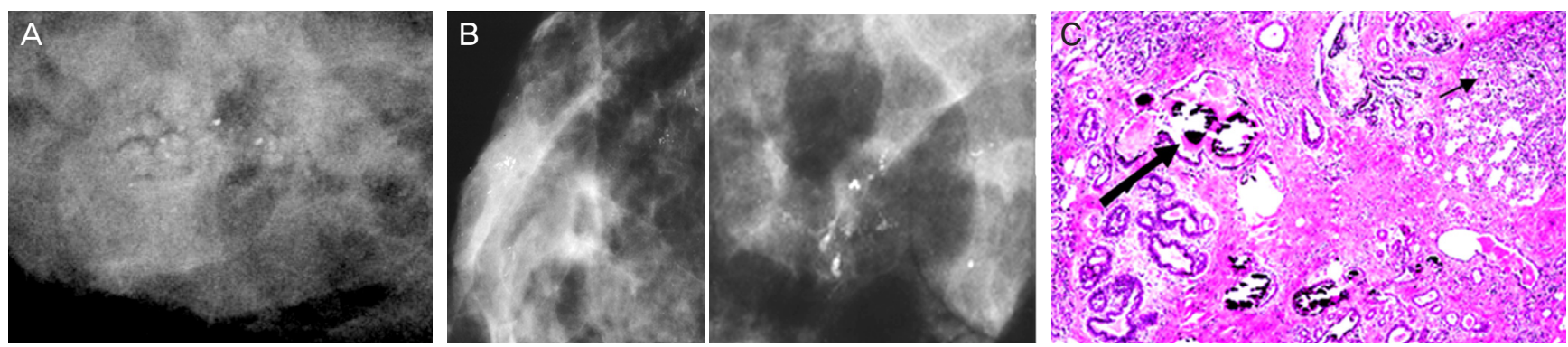

Fig. 5. Microcalcifications during lactation. (A) Image shows new cluster of indeterminate asymmetric microcalcification. (B) Craniocaudal spot-compression magnification mammograms: several clusters of heterogeneous and granular calcifications. Some clusters display linear distribution. (C) Photomicrograph of histopathologic specimen: a Coarse microcalcification group is seen in the dilated duct. The relatively bigger microcalcification (thick arrow) shows in the single duct with homogeneous and eosiophillic feature. The smaller microcalcification (thin arrow) is seen in the lobule $(H \& E, \times 50)$. 


\section{Obstetrics \& Gynecology Science}

Ji Hoon Yu, et al. Breast diseases in pregnancy \& lactation

has a possibility of a severe case that may persist throughout the whole lactation period. Diagnostic cytology tests must be performed for the wounds of nipples by feeding. If the result, physical examination and ultrasound are normal, the follow up test should be recommended in a timely manner.

If it seems to be abnormal in cytology, galactography should be performed especially when the bloody discharge is observed from one duct. However, it is important to help the patient to be relieved because this kind of bloody discharge is a rare symptom of PABC (Figs. 6, 7) [26-28].

\section{3) Galactocele}

Galactocele is a benign lesion, which is mostly detected after a few weeks or months from the time the patient stopped breast feeding, or during lactation or during the 3rd trimester of pregnancy $[11,29]$. This means it is surrounded by the epi-
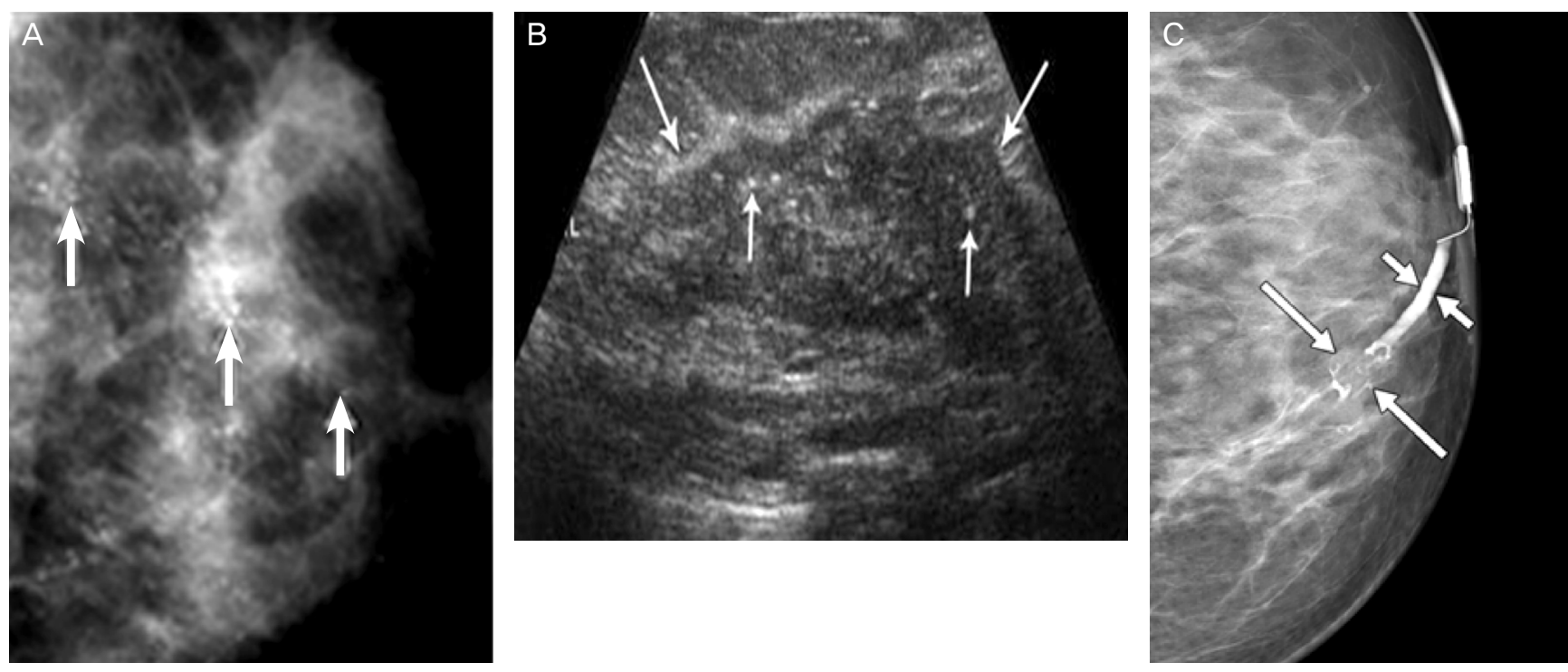

Fig. 6. A woman who presented with palpable mass and bloody nipple discharge at 24 weeks of pregnancy. (A) Magnification view mammogram of left breast in craniocaudal projection: extensive pleomorphic microcalcifications (arrows). (B) Corresponding longitudinal ultrasound image: irregular solid hypoechoic mass (long arrows) with internal calcifications (short arrows) corresponding to mammographic finding. (C) A mammogram of 30 weeks of pregnant woman presented with bloody nipple discharge: Multilobulated filling defect (long arrows), which focally expands duct. Proximal duct is dilated (short arrows).

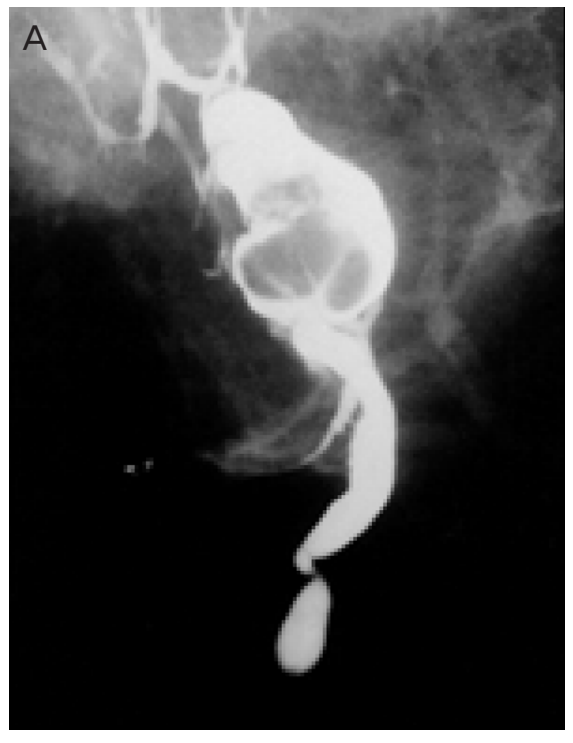

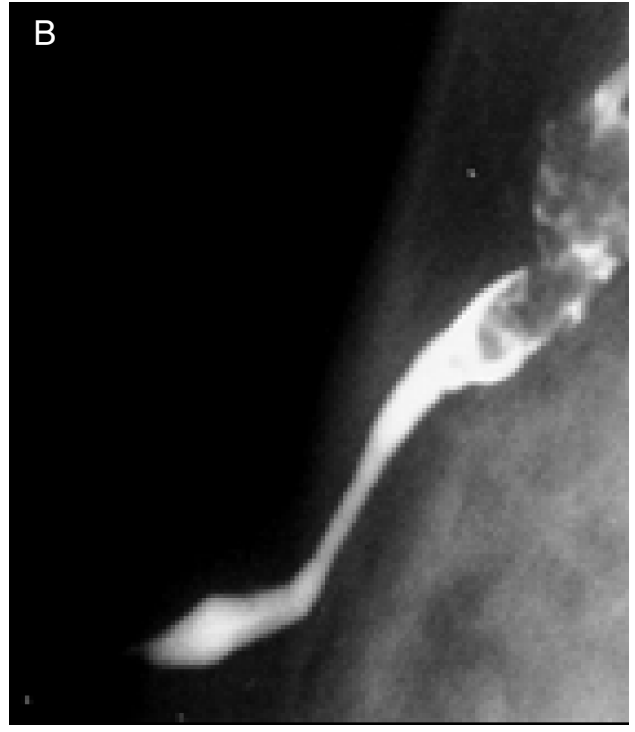

Fig. 7. (A) The galactogram in a lactating woman who presented with bloody nipple discharge: lobular filling defect is seen which is expected to be intraductal papilloma. (B) The galactograms in patients with papillomatosis showing intra-ductal growth in a separate duct. 


\section{Obstetrics \& Gynecology Science}

Vol. 56, No. 3, 2013

thelial cells and myoepithelial cells and contains liquid that is similar to lactate in cystic changed terminal duct and ductules. Most of the galactoceles are found as painless palpable mass which contains protein, fat, lactose in aspiration analysis and are often accompanied by inflammation and necrosis. Therefore, it is considered that the galactocele is formed by the wall fibrosis due to the inflammatory response of extension of lactate ducts. When the contents leak within the breast, chronic inflammation and fat necrosis are observed [30]. Needle aspiration biopsy is helpful for diagnosis and treatment, however, milk-like liquid during lactation and sticky milky contents after lactation, are found in aspiration [29,31]. If it recurrs even after several aspirations, imaging test is needed. Depending on the proportion of fat and protein in breast milk, mammo- graphic findings of galactoceles may vary, which can be seen as follows.

(1) Pseudolipoma: When a higher fat content, seems to be completely radiolucent mass.

(2) Cystic mass with fat-fluid level: Low concentration of fat content rises up and the liquid sinks to the bottom. It is a diagnostic finding that is seen in the mediolateral oblique view of Mammography.

(3) Pseudohamartoma: Galactoceles does not separate lipid from liquid and it is seen radiologic findings which is simliar to hamartoma that contains high viscosity of breast milk [31].

Sonographic findings of galactoceles may also vary depending on the time and site of lesion. In the acute phase, it may appear as an anechoic unilocular simple cyst or a multilocular
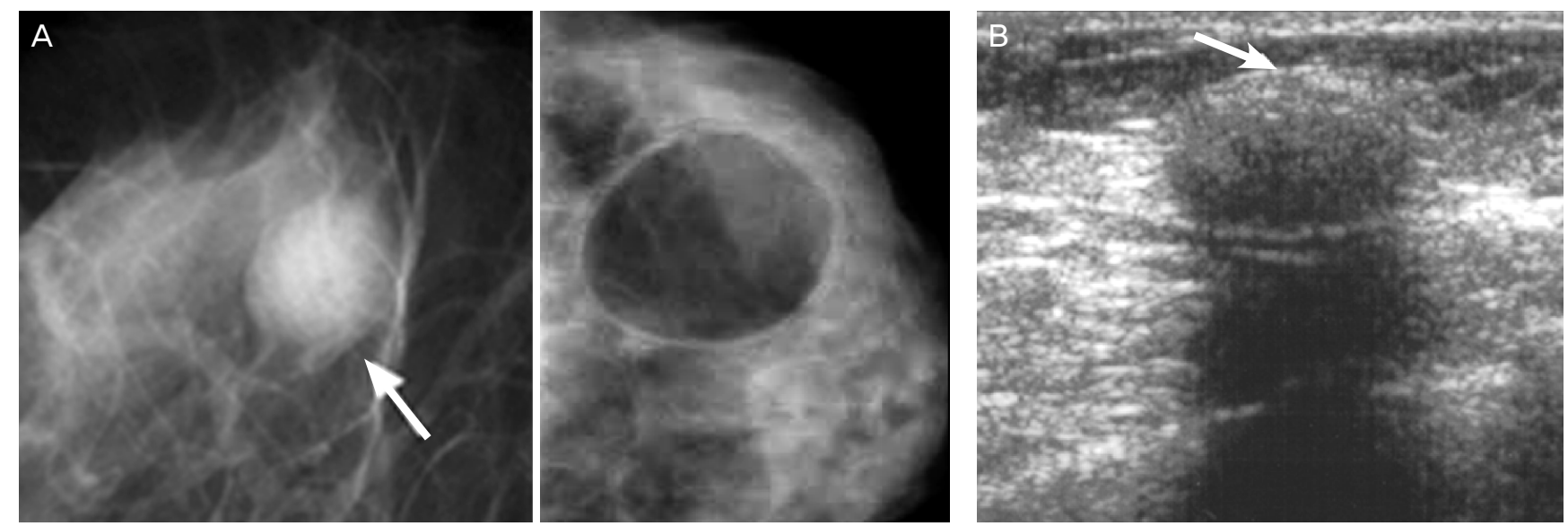

Fig. 8. Pseudolipoma type galactocele. (A) Mammography shows a $1.5 \mathrm{~cm}$ oval circumscribed mass (arrow) at the subareolar region. (B) Sonography shows a $1.5 \mathrm{~cm}$ oval circumscribed hypoechoic nodule with posterior shadowing. An echogenic rim (arrow) can be seen at the anterior margin.
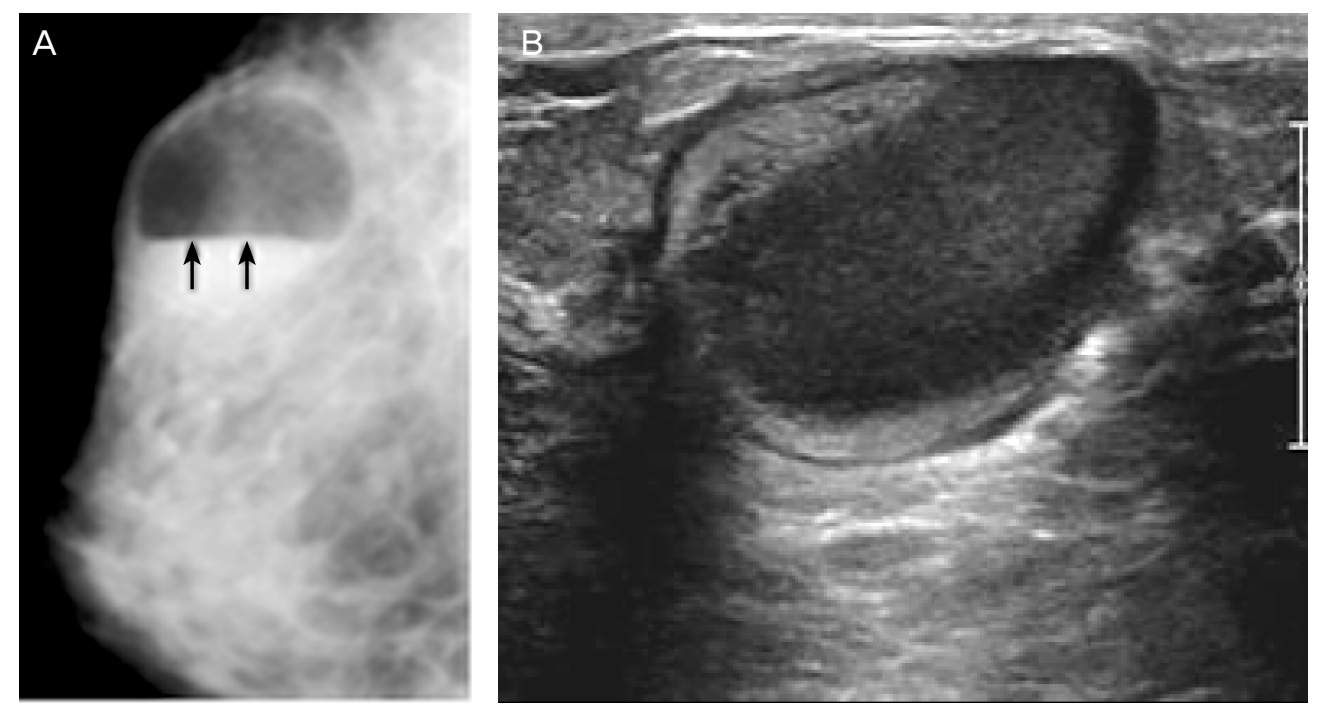

Fig. 9. Galactocele with fat-fluid level. (A) An oval circumscribed cystic mass (arrows) with fatfluid level is imaged in mammogram. (B) Ultrasound image shows the fat-fluid level with high echogenicity of lipid component and low echogenicity of fluid in the same patient. 


\section{Obstetrics \& Gynecology Science}

Ji Hoon Yu, et al. Breast diseases in pregnancy \& lactation
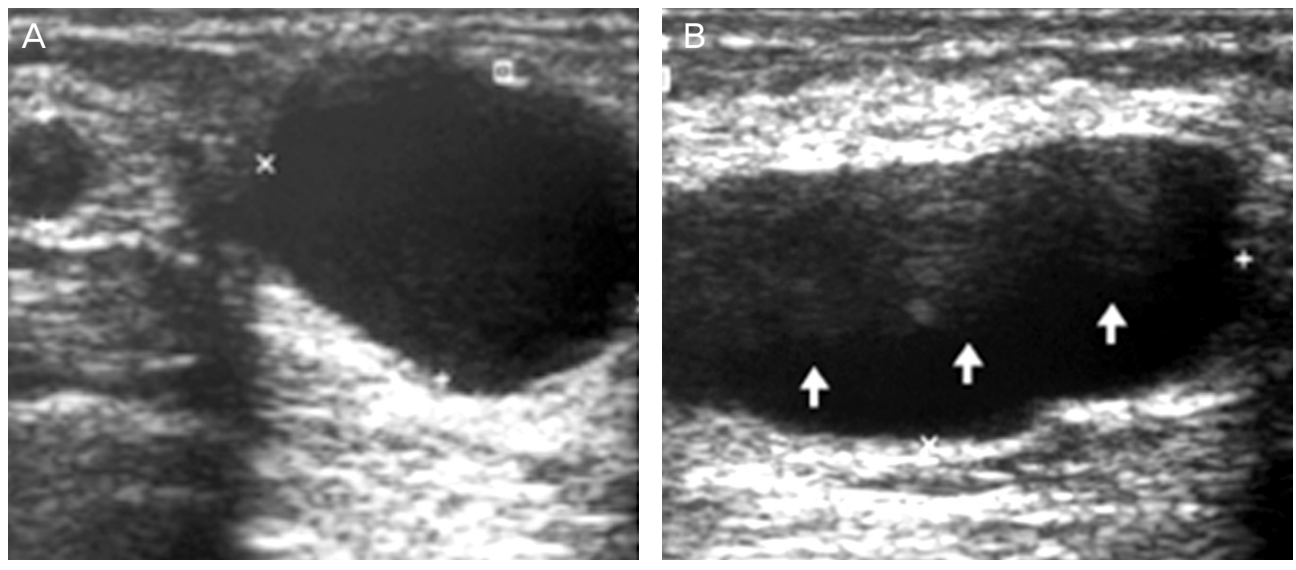

Fig. 10. Galactocele 6 months post delivery which shows various features. (A) Ultrasound (US) image reveals 2 cystic mass: typical galactocele with homogenous anechoic, acoustic attenuation and lateral edge shadowing in bigger cyst. (B) US image shows the lobulated, fatfluid (arrows) galactocele.
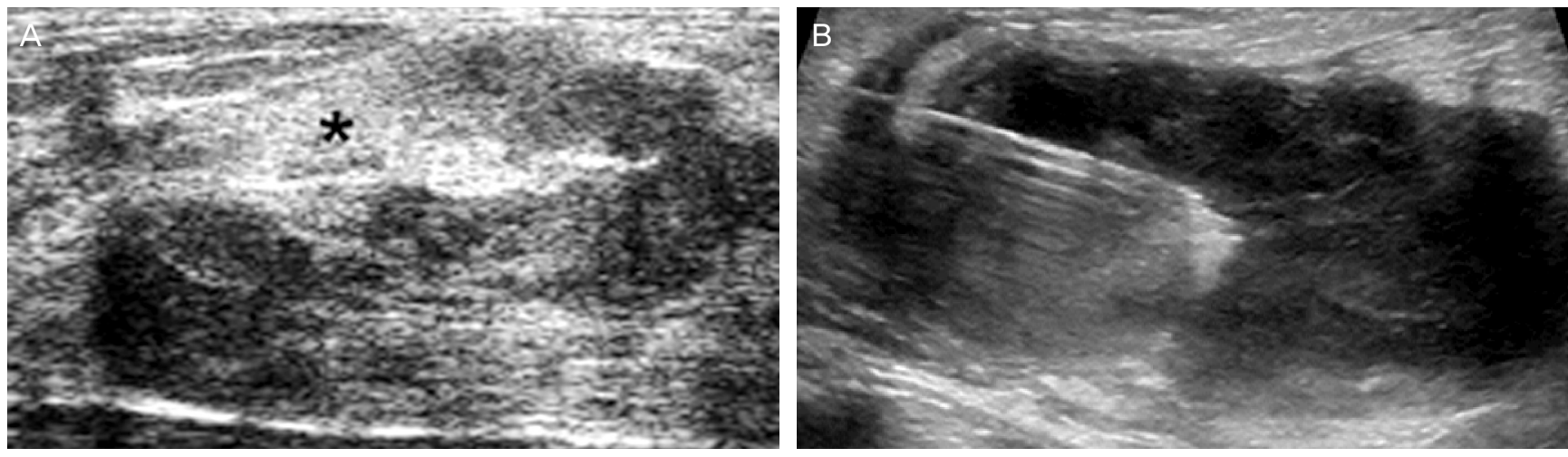

Fig. 11. Infected galactocele: lactating woman who presented with reddish skin changes in the breast. (A) Ultrasound image shows a heterogeneous echoic, irregular margined collection which was suspicious of abscess. (B) Fine-needle aspiration and culture was performed.

cyst with thin septation. It is common multilocular cyst that occurs in peripheral region and it is common unilocular or bilocular cyst that occurs in central region. The intensity of hypoechoic echo increases gradually due to the interface between the fat and water components. In this case, Doppler examination performed by the blood vessels in the center to make sure that no particles moving when you press the transducer lesions may be helpful in the diagnosis. In ultrasound, galactoceles only breast milk composition consists of benign solid masses as shown boundaries if and posterior acoustic enhancement seems clear. A long time later, several ingredients are mixed and if you look inside looks mixed echogenic heterogeneous mass (Figs. 8-10) [11,32-34]. Galactoceles is rich in nutrients, and sometimes it can be infected. This finding is well observed in the ultrasound. Aspiration here, you can see that the purulent fluid and breast milk ingredients are mixed in (Fig. 11). Most natural decay takes over several weeks, but occasionally a more long-lasting.

\section{Inflammatory and infectious diseases}

1) Postpartum mastitis (puerperal mastitis)

It's not common to see infections during pregnancy, but it is often observed in lactation. Staphylococcus aureus and Streptococcus, which are common pathogens present in the nose and throat of newborn babies, may infect the breast via the damaged epithelial cells of the nipple-areola complex during breast feeding. Nipple cracks or abrasions of the skin can be often discovered on the patient's past history. If breast milk is stagnant, it would be a good culture medium and cause symptoms $[24,29,30]$. S. aureus infections, being topical, result in severe clinical symptoms right from the beginning, whereas infections caused by streptococci are diffuse and cause local abscess only in the advanced stage of infection (Figs. 12,13). It is treated well by antibiotics, especially amoxicillin-clavulanate. It is quite rare, but puerperal mastitis by methicillin-resistant $S$. aureus can be very fatal [35-37]. Mammography should not be performed, unless there are 


\section{Obstetrics \& Gynecology Science}

Vol. 56, No. 3, 2013
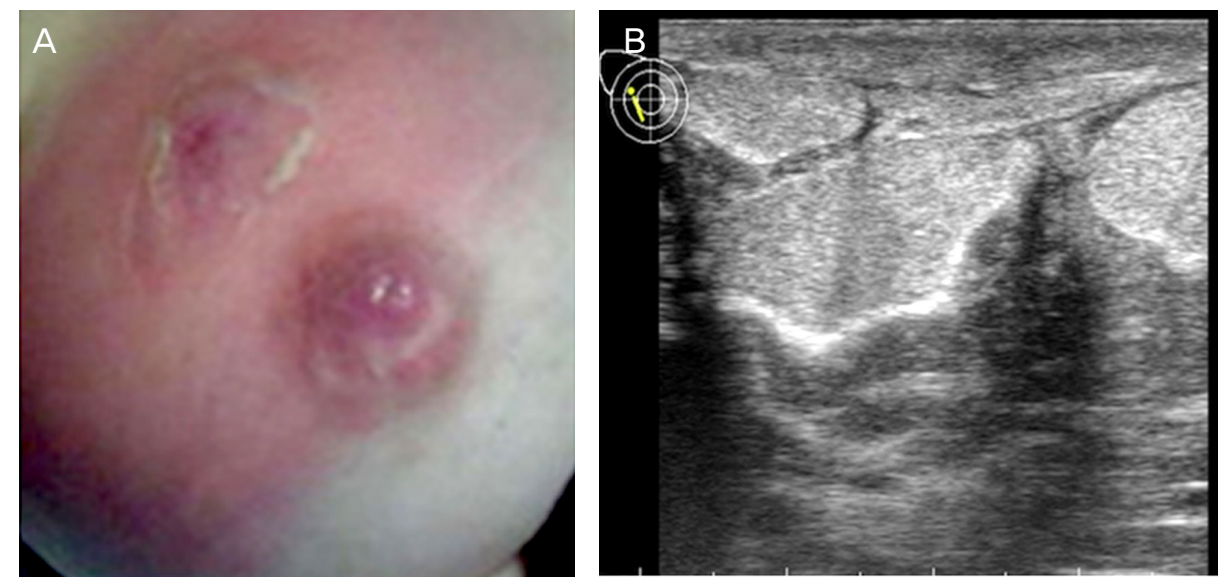

Fig. 12. Puerperal mastitis with abscess formation. (A) Lactational abscess grossly apparent secondary to flaming redness, hemorrhagic area, swelling, and peeling skin. (B) Ultrasound image shows large mass and purulent material was obtained by fine-needle aspiration.
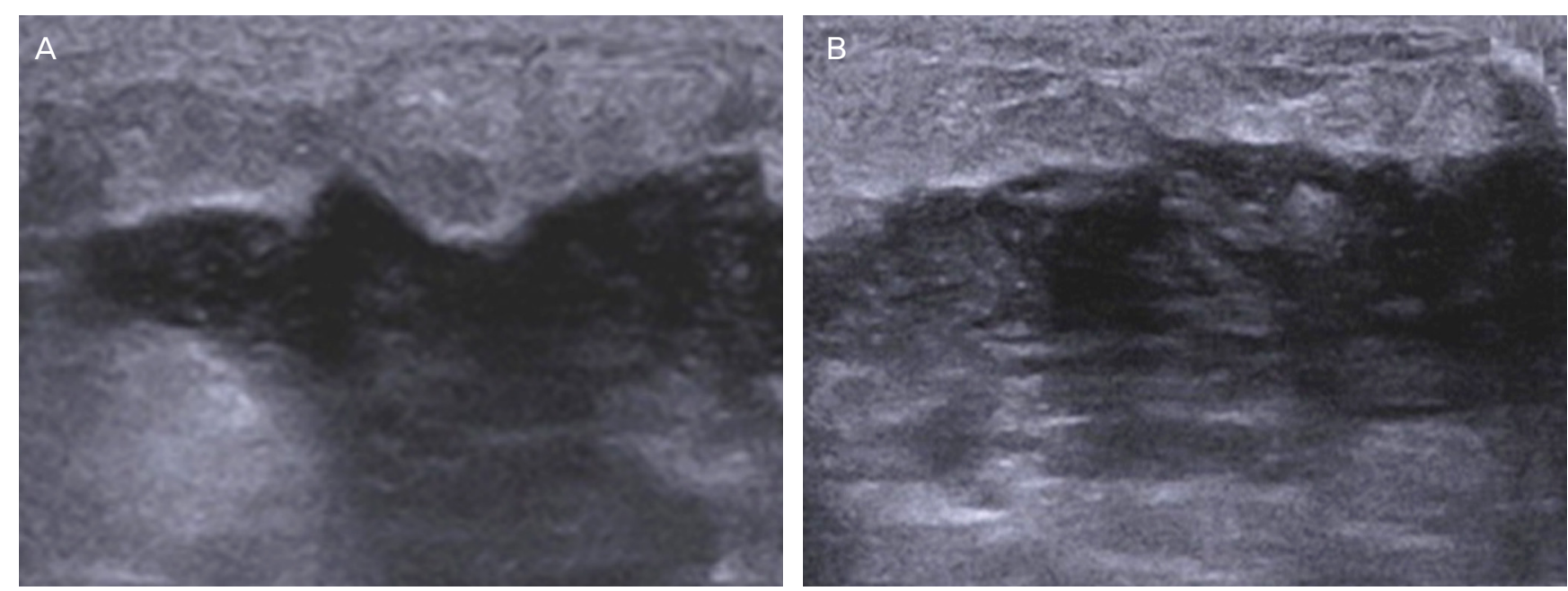

Fig. 13. Ultrasound findings in puerperal mastitis. Early stage mastitis shows various features that is presented with thickness of skin and subcutaneous layer, and irregular border between subcutaneous layer and parenchyme. (A) US shows irregular margin and hypoechoic lesion. (B) If abscess is develop, hypoechoic or anechoic fluid collections can be seen. Irregular margin and echoic lesion can be also seen along with acoustic enhancement.

suspicious malignant findings. The reason is that it mostly shows thickening of the skin and fibrous tissue even though it is very severe mastitis. Moreover, it is rare to discover other severe abnormalities. If there is abscess formation suspected, the ultrasound examination is first required for the diagnosis and treatment. Irregular boudaries, hypoechoic or anechoic mass, thick, irregular walls, posterior acoustic enhancement, and liquid debris (fluid-debris) shades can be observed in the abscess. Sometimes the air in abscess can cause bright reflection. These hyperechoic dots floating point is the differentiation of malignant. Mastitis in lactation abscess developed in the subacute form, periarthritis $[38,39]$. Abscess is easily treated by incision drainage. If the abscess lesion size is less than $3 \mathrm{~cm}$, it can be treated with 14 to 21 gauge needle aspiration. If the abscess lesion size is $3 \mathrm{~cm}$ or more, it can be aspirated with the 6 to $8 \mathrm{Fr}$ catheter drainage or surgical drainage. Before doing this, it is important to dry up the abscess first. It is necessary that examiner should irrigate the cavity with normal saline under local anesthesia after the drainage to prevent recurrence [38-40]. After treatment, continuing breast feeding helps improve inflammation and promote drainage. Also, breast feeding can be safely performed during antibiotics therapy $[29,35]$. If there is no improvement despite these treatments, examiner should suspect tumor and perform cytology test and biopsy.

\section{2) Granulomatous mastitis}

Granulomatous mastitis occurs mainly in young women, 


\section{Obstetrics \& Gynecology Science}

Ji Hoon Yu, et al. Breast diseases in pregnancy \& lactation

and it is an uncommon type which mainly occurs within five years after pregnancy [41-43]. It exhibits specific histological findings characterized by non-caseating (noncaseating), non-vascular (nonvasculitic) granulomatous inflammatory changes, which can be noted in the center of the lobules. Mammographic findings are diverse from normal to benign with focally asymmetric shadow and malignant. Sonographic findings helpful in diagnosis are multiple appearances, which often show hypoechoic and sometimes large hypoechoic mass in adjacent lactiferous gland (Fig. 14) [43]. However, it requires special attention in diagnosis because it is not well differentiated from malignancy, and reactive lymphadenopathy is observed in about $15 \%$. Local excision can be a treatment [40-46], but sometimes it disappears naturally. Therefore close follow-up is necessary [47].

\section{3) Juvenile papillomatosis of the breast}

Benign proliferative lesion is a common type because of the influence of hormones during pregnancy and lactation. Juvenile papillomatosis of the breast rarely occurs in young women, and it is characterized by ductal hyperplasia and papillary proliferation of the wall surrounding its sac [48]. It is seen as a hypoechoic mass with an unclear margin in an ultrasonogram, and no specific findings, except an asymmetric shadow, is seen in a mammogram; however, sometimes microcalcification can be observed. The treatment is a surgical resection. It is important to check if the resection margin is completely negative when it comes to preventing recurrence.

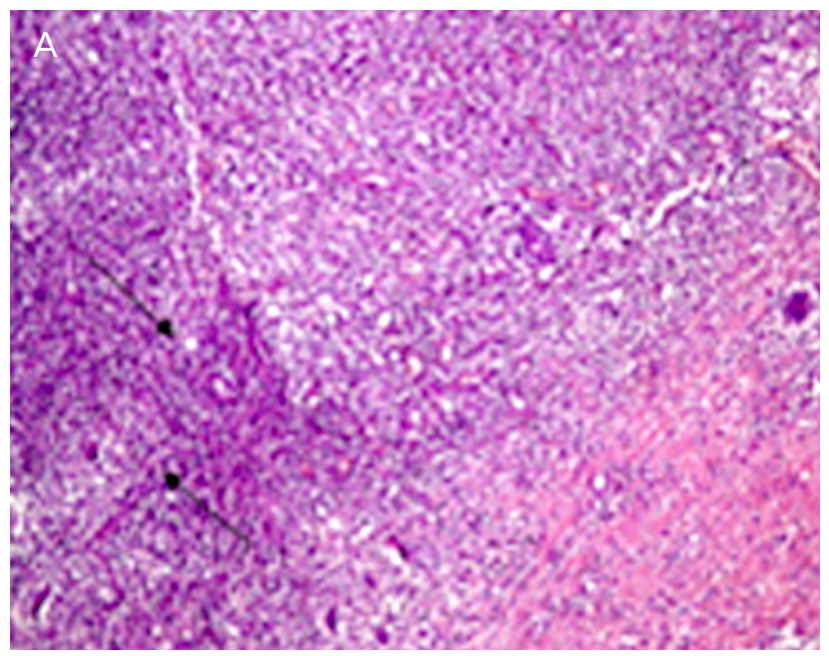

\section{Benign tumor}

1) Tumors related to pregnancy and lactation Lactating adenoma is a benign tumor mainly caused by the physiological changes that occur during pregnancy and lactation. This typically occurs during feeding or the third trimester of pregnancy. Lactating adenoma is sometimes interpreted as a variant of fibroadenoma, tubular adenoma, or lobular hyperplasia, which are also caused by physiological changes [49-51]. Fibroadenoma is mixed with stromal and epithelial components. Lactating adenomas, however, only consists of epithelial component. Grossly, it seems to be a certain boundary and elastic mass. Histologically, it is densely packed with lobules, which are separated from each other by a thin connective tissue. Lactating adenoma is composed of acinars and mature thin tubes and filled with secretion is softer than a fibroadenoma The physiological changes that occurs in the surrounding normal parenchyma takes place in the lesions of the internal secretion and secretory hyperplasia appears [4951]. Lactating adenoma can naturally disappear at the end of pregnancy or lactation. It may also disappear by necrosis, like a fibroadenoma [52]. Most of Lactating adenoma does not relapse after complete resection. Lactating adenoma accompanying malignant lesions is very rare. And it does not increase the risk of breast cancer. It is difficult to distinguish between a lactating adenoma and a fibroadenoma by imaging. A radiolucent or hyperechoic area, which indicates fat content of breast milk, according to lactation hyperplasia, can be seen on mammography or ultrasonography and is useful in diagnosis (Fig. 15). It appears to be a small hypoechoic mass, which is difficult to distinguish from the surrounding tissue on

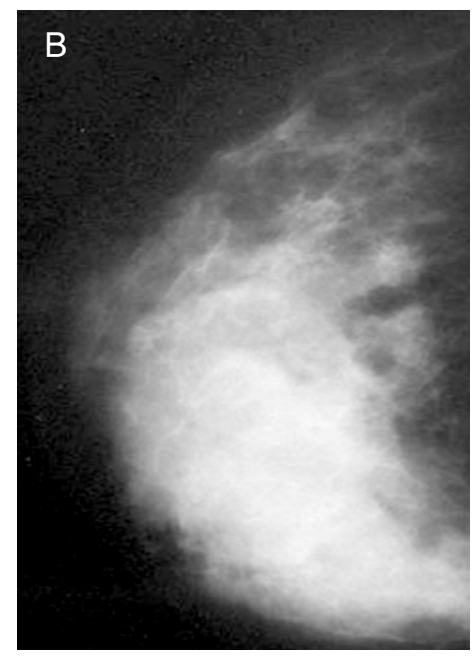

Fig. 14. Granulomatous mastitis after pregnancy. (A) Photomicrograph (enlarged, H\&E, $\times 10$ ) shows epitheloid and giant cell granulomas (arrows) in polymorphous inflammatory infiltrate. (B) Mammogram shows irregular enhanced mass almost filled the right breast. 


\title{
Obstetrics \& Gynecology Science
}

\author{
Vol. 56, No. 3, 2013
}

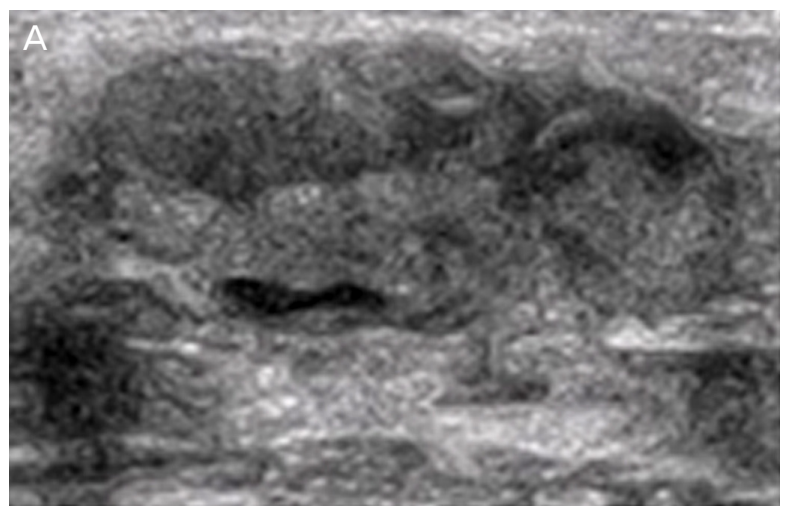

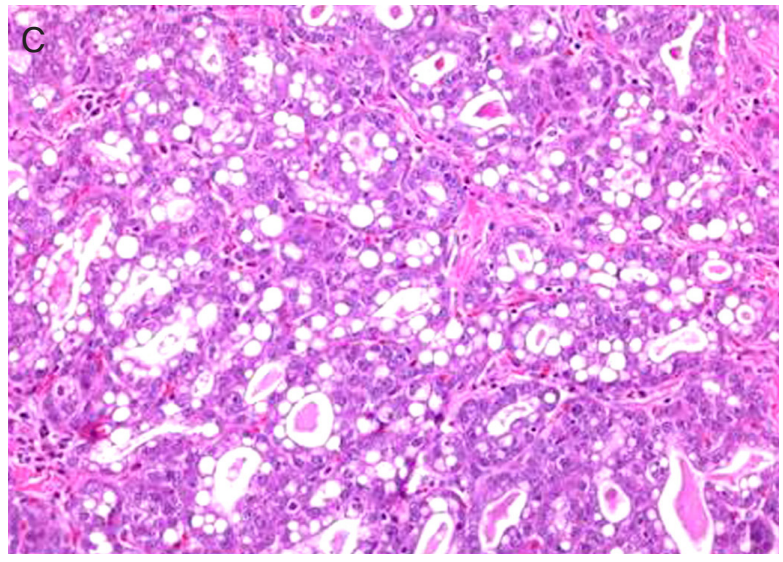

ultrasonography. Moreover, because of its posterior acoustic enhancement and hormonal changes, it appears hypervascular in color or output Doppler. Occasionally, the differential diagnosis of malignant lesions is difficult mainly due to unclear boundaries, microlobulated periphery, reducing posterior acoustic effect, structural heterogeneity. And it occurred by the necrosis of lactating adenoma [11,53-55].

2) Morphologic and physiologic changes in fibroadenomas secondary to pregnancy and lactation

\section{(1) Growing fibroadenoma}

Fibroadenoma is the most frequent lesion found during pregnancy and the period of lactation. It can be formed before pregnancy, however, there are many instances wherein it is undetected because it is not palpable or breast screening inspection is not performed on young women. Fibroadenoma increases in size during pregnancy because of its sensitivity to hormone levels. Imaging findings of fibroadenoma is not very different during pregnancy, however, findings such as dilation of lactiferous ducts and increase in blood of flow is very similar to complex fibroadenoma (Fig. 16) $[29,56,57]$. When

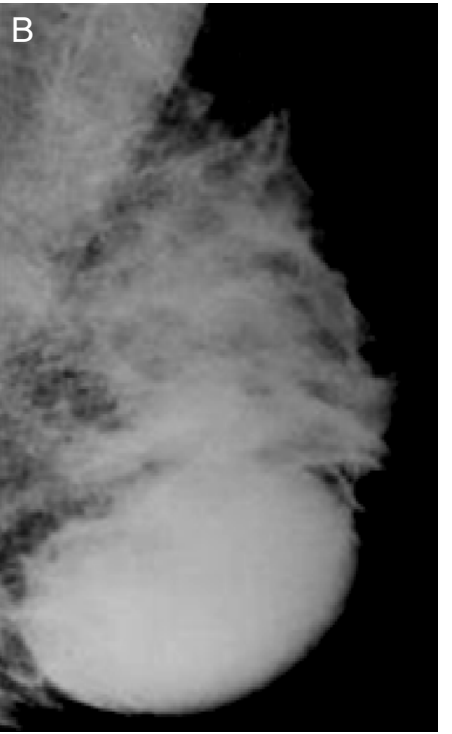

Fig. 15. Lactating adenoma. (A) Ultrasound image demonstrates oval, well defined, regular margined mass. (B) Mammogram shows an oval circumscribed mass in the left lower breast. (C) The lobules are lined by actively secreting epithelial cells with vacuolated cytoplasm. Secretions may accumulate in the glands. The cells have basophilic cytoplasm, hyperchromatic nuclei with prominent nucleoli, and inconspicuous myoepithelial cell layer $(H \& E, \times 400)$.

performing fine needle aspiration for diagnosing palpable fibroadenoma, you must consider the physiological changes of cells during pregnancy [58]. Central biopsy is also appropriate and must be carefully done to avoid hemorrhage, lacto fistula and infection.

\section{(2) Fibroadenoma with infarction}

Spontaneous necrosis of fibroadenoma is very rare, but it is sometimes observed during pregnancy or lactation. It can be presumed when there is sudden pain during the third trimester or during birth. The cause is embolism within the vessels and it shows more borderlines of lobules and mixes echos and shows posterior shadow depending on the degree of necrosis. If necrosis is more extensive, central biopsy must be performed to differentiate from a malignant lesion [30,59-61].

(3) Fibroadenoma with secretory hyperplasia or lactational change

During pregnancy, hormone-sensitive breast parenchyma of fibroadenoma is stimulated by pregnancy hormones leading to secretory hyperplasia. This is very similar to the phenomena 


\section{Obstetrics \& Gynecology Science}

Ji Hoon Yu, et al. Breast diseases in pregnancy \& lactation
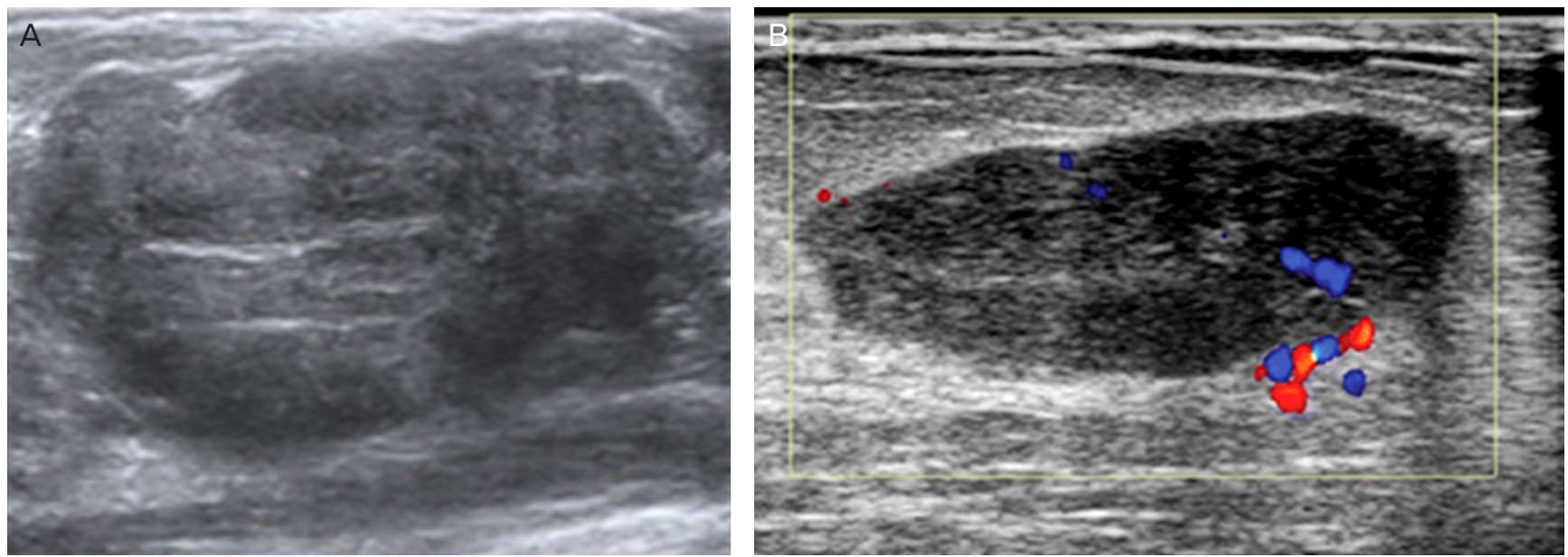

Fig. 16. Fibroadenoma. (A) Aside from cystic lesion, fibroadenoma shows internal echogenicity and fibroadenoma can not be distinguished from malignant lesion perfectly. (B) Color Doppler Ultrasound image shows a fibroadenoma with increased vascularity and lobulated hypoechoic mass.

seen in lactating adenoma, so it is very difficult to distinguish between both. When fibroadenoma undergoes changes during lactiferous phase, there can be lactation during sucking and it is noted that this phenomena is not seclusive to breast cysts. Similar to complex fibroadenoma, it is diagnosed based on the findings of secretory hyperplasia, which appears as mixed echo, and dilated lactiferous ducts and cysts. Furthermore, calcification may sometimes be detected during breast imaging.

\section{Malignant tumor (PABC)}

\section{1) Introduction}

PABC is defined as breast cancer that occurred during pregnancy and after delivery within one year, represents up to approximately $3 \%$ of all breast cancers, occurring in one incidence per 3,000 to 10,000 pregnancy. Delay of childbirth age shows increased prevalence and advanced stage at the time of diagnosis and poor prognosis and seems that more than $50 \%$ are high-grade tumors $[29,62,63]$. And large number of them are form of inflammatory tumor and shows in more than $50 \%$ lymph node metastasis, negative at hormone receptor and positive at HER2/neu $[62,63]$. Late diagnosis of tumors owing to the biological effects of pregnancy results in poor prognosis and rapid tumor growth; recurrence is common within 2 to 3 years of the diagnosis $[29,62,63]$.

Mostly palpable lesions and clinical symptoms are visible swelling, redness, and diffuse mastosis at locally advanced carcinoma $[29,62,63]$. The imaging findings of breast cancer in non-pregnant women are not significantly different from those in pregnant women due to the increase in glandular density. Even in non-pregnant women, mammography has low sensitivity, and ultrasound is considered a better diagnostic tool [7-12].

\section{2) Cause of delayed diagnosis}

The mammary gland undergoes clinical and physiological changes during pregnancy, making imaging diagnosis difficult. The majority of patients with advanced stage looks so delayed diagnosis is as follows $[64,65]$.

(1) Young women who are not a screening test.

(2) Self-examination is difficult and is not performed frequently.

(3) The clinical examination is difficult because of increased blood flow and dense mammary tissues.

(4) Until delivery they are not good at follow up test.

(5) Breast care at the department of obstetrics and gynecology does not enforce.

(6) Reluctant to biopsy during pregnancy.

During pregnancy is known to be delayed an average of 5 to 7 months of breast cancer diagnosis, whenever be delayed one month diagnosis shows increased by approximately $0.9 \%$ to $1.8 \%$ of axillary lymph node metastasis [66].

\section{3) Symptoms}

In most cases, it appears as a breast mass with no associated pain, and sometimes, it can be found on breast examination in the absence of breast feeding [66]. During the third trimes- 


\title{
Obstetrics \& Gynecology Science
}

\author{
Vol. 56, No. 3, 2013
}

ter of pregnancy, hemoid secretion is often seen due to loss of epithelial cells alike papilloma in lactiferous drifts and this is a common symptom.

Cytological examination will be carried out when hemoid secretion is continued more than 2 months after delivering.

\section{4) Diagnosis}

Although mammography is not effective in pregnancy because physiological changes decreased sensitivity and specificity, it is performed suspected malignancy. $68 \%$ to $74 \%$ of PABC has abnormal findings with mammography and $90 \%$ of PABC has Breast Imaging Reporting and Data System (BIRADS)
3 to 4 score. During pregnancy, ultrasound seems the most effective imaging studies in the diagnosis of breast disease. And it's sensitivity to the breast disease is $93 \%$ to $98 \%$ (Figs. 17, 18). Complex echo pattern, posterior acoustic enhancement is a common finding in the PABC compared with non-pregnancy breast cancer. Necrosis or cystic change is seen in the carcinoma present non-echo pattern and posterior acoustic enhancement because tumor grows up quickly by stimulation of the hormonal changes in pregnancy.

\section{5) PABC in carrier with BRCA mutation}

Carriers with breast cancer (BRCA)1 or BRCA2 mutation are
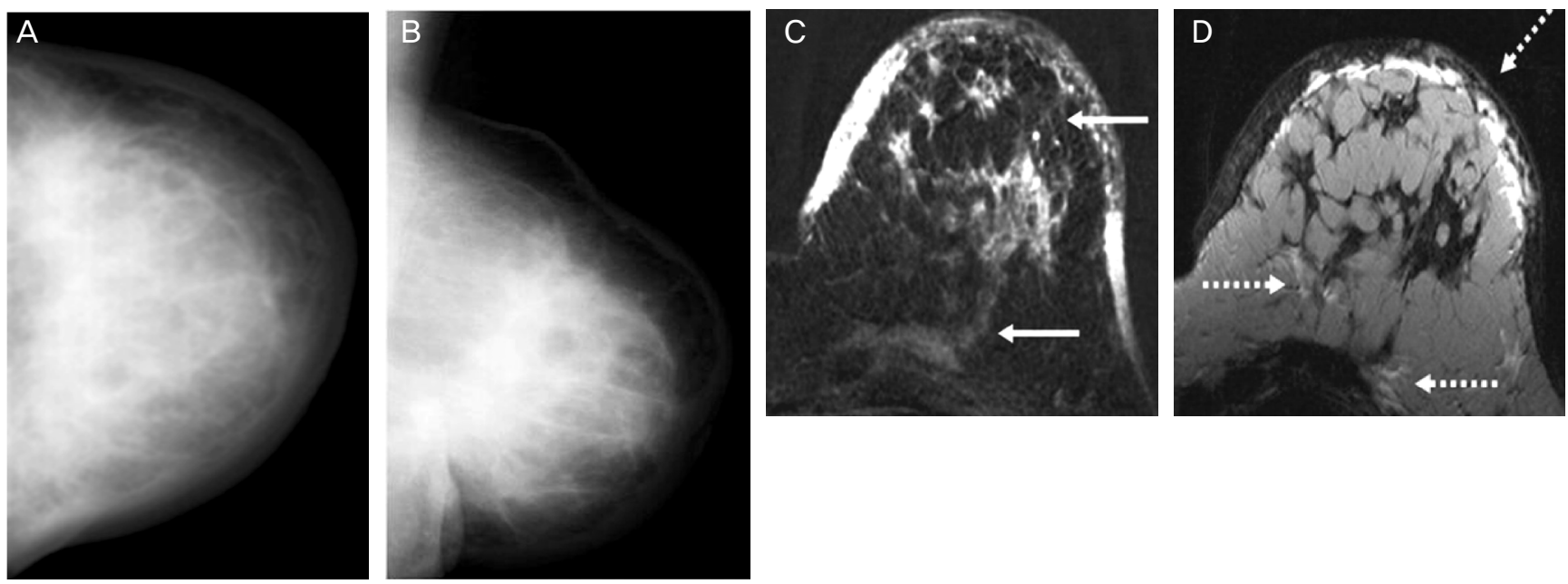

Fig. 17. Inflammatory carcinoma during pregnancy. (A) Craniocaudal view. (B) Mediolateral-oblique view: mammogram shows a mark diffuse increase in parenchymal density with skin thickening. (C) Subtraction 1 minute after bolus injection-the diffuse enhancement infiltrating the skin and the pectoralis muscle (continuous arrows). (D) T2-weighted image-edema in a cutaneous/subcutaneous, diffuse and prepectoral localization (discontinuous arrows).
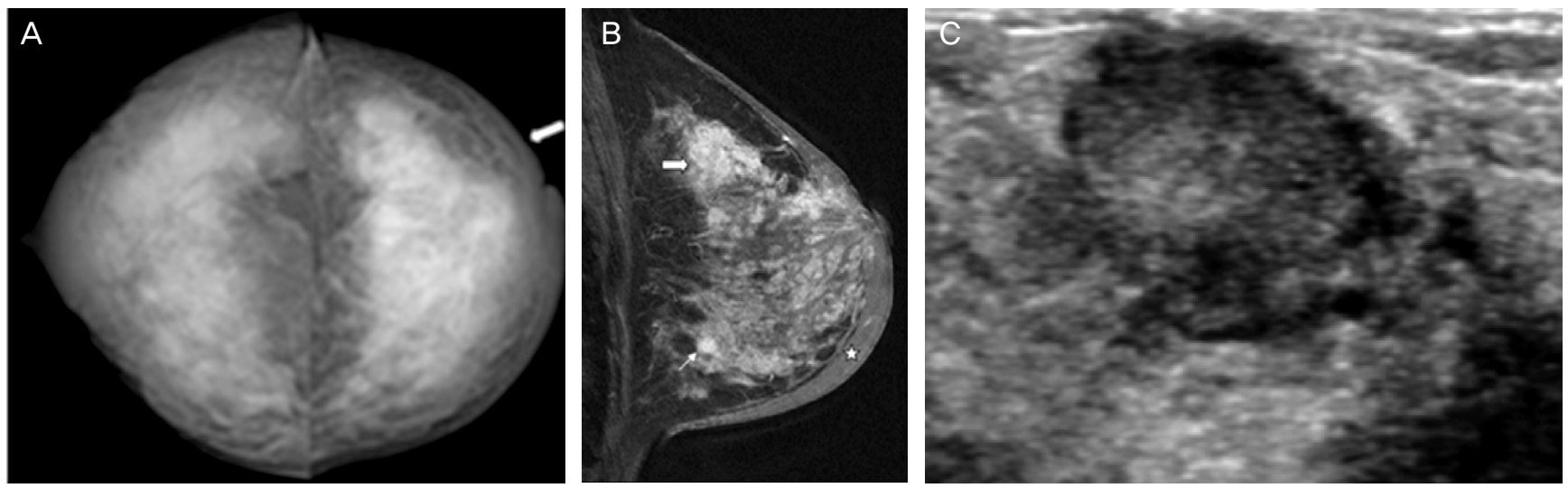

Fig. 18. Pregnancy-associated breast cancer in a lactating woman who is presented with paeau d'orange skin. (A) Bilateral craniocaudal mammogram: severe dense breast with hypertrophic skin. (B) Mediolateral-oblique view: multiple mass (thick and thin arrows). (C) Ultrasound image in a lactating woman presented with palpable mass 9 months post delivery: it shows taller than wide mixed echogeic lesion revealed with invasive ductal carcinoma. 


\section{Obstetrics \& Gynecology Science}

Ji Hoon Yu, et al. Breast diseases in pregnancy \& lactation

at high risk for breast cancer. Therefore carriers with BRCA1 or BRCA2 mutation certainly needs to undergo strict clinical and image examination before and after pregnancy. This strict examination uses ultrasonography and MRI, but ultrasonography is more useful than MRI because the latter is difficult to find during the period of lactation (Fig. 19).

According to former studies, the PABC prevalence of carrier with BRCA1 mutation is higher than BRCA2 mutation [67]. Carriers of mutations in the BRCA1 or BRCA2 genes who have parity have an increased risk of $P A B C$ than those who do not have parity before the age of 40 years, and pregnancy at an early age does not decrease the prevalence [68]. But it was recently reported by International BRCA1/2 Carrier Cohort Study (IBCCS) that carriers with BRCA1, BRCA2 malignant and control group has decreased the risk of being malignant after the age of 40 years [69].

\section{6) Treatment}

\section{(1) Pregnancy interruption}

In the past, due to the adverse affects of tumor growth and proliferation due to increasing hormone levels during pregnancy, therapeutic abortion was encouraged. But according to several studies, the therapeutic abortion does not improve the prognosis. The reason is that the mammary gland of most of $P A B C$ is hormone receptor negative and imcomplete growth and division occur in the point at which the pregnancy ends. For this reason therapeutic abortion brings about growth of tumor. So termination of pregnancy should be considered in case of a very aggressive tumor or receptor positive.

\section{(2) Staging and histologic types}

According to stage by Tumor-Node-Metastasis (TNM) system of American Joint Committee on Cancer, the most common histologic type is infiltrating ductal adenocarcinoma for $80 \%$.

\section{(3) Surgical treatment}

During pregnancy axillary disection can be performed safely with modified radical mastectomy and lympectomy. Breast parenchyma can be preserved in the following 2 ways during pregnancy. First, conserving surgery can be performed in the second trimester of pregnancy, and radiation therapy, after delivery. Second, conservation therapy and neoadjuvant chemotherapy can be performed in the second trimester, and radiation therapy, after delivery.

\section{(4) Chemotheraphy}

The majority of anticancer drugs that are administered to a PABC patient can cause teratogenesis and mutation that are related to intrauterine growth retardation (IUGR), deformity, still birth. Teratogenesis increases $20 \%$ especially in the first trimester of pregnancy. Furthermore, due to the physiological changes during pregnancy, i.e., increased renal blood flow, glomerular transmittance, and creatinine, the pharmacokinetics of a cytotoxic drug are altered. Moreover, the drug may be accumulated in the amniotic fluid, which may interrupt its excretion. In general, the cytotoxic drug crosses the placenta, but do not know how to pass suspension. However, because
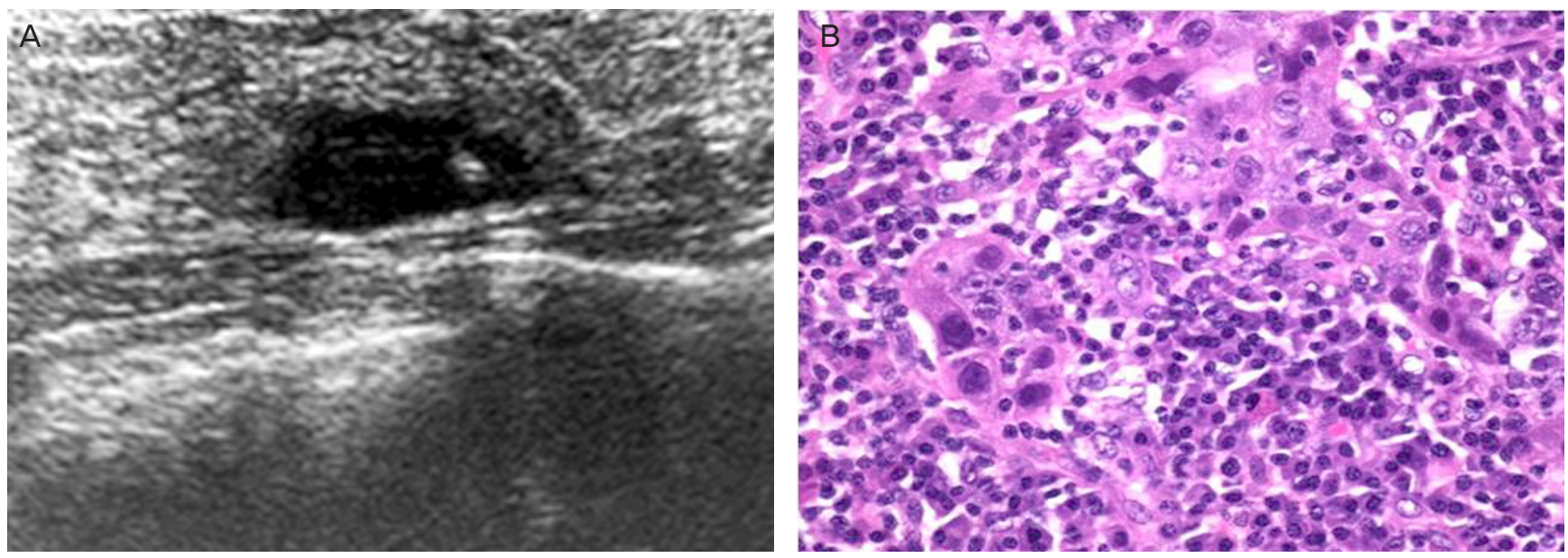

Fig. 19. Atypical medullary carcinoma of the breast with cartilaginous metaplasia. (A) Ultrasound image reveals lobulated hypoechoic lesion in BRCA1 germline muation patient. (B) Higher magnification view of the previous slide shows the highly anaplastic tumor cells in a background of lymphoplasmacytic infiltrate $(H \& E, \times 200)$. 


\title{
Obstetrics \& Gynecology Science
}

\author{
Vol. 56, No. 3, 2013
}

teratogenic in first trimester, 5 to 10 weeks attention and 13 weeks after the safety. Methotrexate is prohibited because of the high risk of contraindication for teratogenesis and miscarriage. Drugs belonging to Food and Drug Administration category D, such as cyclophosphamide, fluorouracil, and cisplatinum, affect teratogenesis in the first trimester, but rarely have an adverse effect during the second and third trimesters. In general, taxanes and trastuzumab are considered safe during pregnancy; however, more studies are needed to confirm their safety.

\section{(5) Hormone therapy}

Most PABC are hormone receptor negative, and in these patients, it is necessary to administer tamoxifen. However, this medicine is prohibited during pregnancy, because it is related to colporrhagia, natural abortion, stillbirth, and malformation. If necessary, it would be recommended to use after the delivery [70].

\section{(6) Radiotherapy}

Even a little radiation, which can be hardly detected, could be fatal to the infant. Pregnant women are most sensitive to radiation during the first 10 to 38 days of pregnancy. During this period, radiation can cause fetal abnormalities such as microencephaly, anencephaly, ocular damage, and clubfoot.

According to the pregnancy period, Mother's body surface is increasing. Therefore, the quantity of the radiation which the infant absorbs depends on the physiological changes from Mother. For example, if radiation of 5,000 cGy is measured in Mother's breast, the infant is exposed to the radiation of 10 to 15 cGy in the first-quarter and to the radiation of more than a hundred in the third-quarter. Consequently, it is recommended

Table 1. Treatment based on pregnancy trimester during which breast cancer is diagnosed

\begin{tabular}{|c|c|}
\hline \multirow[t]{3}{*}{ 1st trimester } & Discuss pregnancy termination \\
\hline & Mastectomy+axillary dissection \\
\hline & $\begin{array}{l}\text { Chemotherapy during } 2 \text { nd trimester, } \\
\text { radiotherapy+hormone therapy postpartum }\end{array}$ \\
\hline \multirow[t]{2}{*}{ 2nd trimester } & $\begin{array}{l}\text { Mastectomy or segmentectomy+axillary } \\
\text { dissection }\end{array}$ \\
\hline & $\begin{array}{l}\text { Neoadjuvant chemotherapy and surgery } \\
\text { postpartum }\end{array}$ \\
\hline \multirow[t]{2}{*}{ 3rd trimester } & $\begin{array}{l}\text { Mastectomy or segmentectomy+axillary } \\
\text { dissection }\end{array}$ \\
\hline & Adjuvant treatment postpartum \\
\hline
\end{tabular}

that radiotherapy should folllow after giving birth (Table 1).

\section{Conclusion}

Breast lesions that are detected during pregnancy or nursing are not very different from those detected in non-pregnant women. But, it is difficult to diagnose these lesions in pregnant women due to the hormone-induced physiological changes occurring in the breast.

However given enough understanding and knowledge about special clinical and imaging features in pregnancy and having aggressive approach or action toward these symptoms accordingly it will be helpful to treat and diagnose.

\section{Acknowledgments}

This research was supported by research funds from Chosun University, 2008.

\section{References}

1. Kopans DB. Breast imaging. 2th ed. Philadelphia (PA): Lippincott-Raven; 1998.

2. Salazar H, Tobon H, Josimovich JB. Developmental, gestational and postgestational modifications of the human breast. Clin Obstet Gynecol 1975;18:113-37.

3. Rosen PP. Anatomic and physiologic morphology. In: Rosen PP, editor. Rosen's breast pathology. 2nd ed. Philadelphia (PA): Lippincott-Raven; 2001. p.1-21.

4. Vorherr H. Human lactation and breast feeding. In: Larson BL, editor. Lactation: a comprehensive treatise. 2nd ed. New York (NY): Academic Press; 1978. p.182-280.

5. Neville MC. Physiology of lactation. Clin Perinatol 1999;26:251-79.

6. Neville MC. Anatomy and physiology of lactation. Pediatr Clin North Am 2001;48:13-34.

7. Hogge JP, De Paredes ES, Magnant CM, Lage J. Imaging and Management of Breast Masses During Pregnancy and Lactation. Breast J 1999;5:272-83.

8. Liberman L, Giess CS, Dershaw DD, Deutch BM, Petrek JA. Imaging of pregnancy-associated breast cancer. Radiology 1994;191:245-8. 


\section{Obstetrics \& Gynecology Science}

Ji Hoon Yu, et al. Breast diseases in pregnancy \& lactation

9. Ahn BY, Kim HH, Moon WK, Pisano ED, Kim HS, Cha ES, et al. Pregnancy- and lactation-associated breast cancer: mammographic and sonographic findings. J Ultrasound Med 2003;22:491-7.

10. Samuels TH, Liu FF, Yaffe M, Haider M. Gestational breast cancer. Can Assoc Radiol J 1998;49:172-80.

11. Son EJ, Oh KK, Kim EK. Pregnancy-associated breast disease: radiologic features and diagnostic dilemmas. Yonsei Med J 2006;47:34-42.

12. Yang WT, Dryden MJ, Gwyn K, Whitman GJ, Theriault R. Imaging of breast cancer diagnosed and treated with chemotherapy during pregnancy. Radiology 2006;239:52-60.

13. Greskovich JF Jr, Macklis RM. Radiation therapy in pregnancy: risk calculation and risk minimization. Semin Oncol 2000;27:633-45.

14. Osei EK, Faulkner K. Fetal doses from radiological examinations. Br J Radiol 1999;72:773-80.

15. Kopans DB. Mammography and radiation risk. In: Janower ML, Linton OW, editors. Radiation risk: a primer. Reston (VA): American College of Radiology, 1996. p.21-2.

16. Kanal E, Borgstede JP, Barkovich AJ, Bell C, Bradley WG, Felmlee JP, et al. American College of Radiology White Paper on MR Safety. AJR Am J Roentgenol 2002;178:1335-47.

17. De Wilde JP, Rivers AW, Price DL. A review of the current use of magnetic resonance imaging in pregnancy and safety implications for the fetus. Prog Biophys Mol Biol 2005;87:335-53.

18. Nagayama $M$, Watanabe $Y$, Okumura $A$, Amoh $Y$, Nakashita $S$, Dodo Y. Fast MR imaging in obstetrics. Radiographics 2002;22:563-80.

19. Webb JA, Thomsen HS, Morcos SK; Members of Contrast Media Safety Committee of European Society of Urogenital Radiology (ESUR). The use of iodinated and gadolinium contrast media during pregnancy and lactation. Eur Radiol 2005;15:1234-40.

20. Mitre BK, Kanbour Al, Mauser N. Fine needle aspiration biopsy of breast carcinoma in pregnancy and lactation. Acta Cytol 1997;41:1121-30.

21. Gupta RK, McHutchison AG, Dowle CS, Simpson JS. Fineneedle aspiration cytodiagnosis of breast masses in pregnant and lactating women and its impact on management. Diagn Cytopathol 1993;9:156-9.

22. Schackmuth EM, Harlow CL, Norton LW. Milk fistula: a complication after core breast biopsy. AJR Am J Roentgenol 1993;161:961-2.

23. Stucker DT, Ikeda DM, Hartman AR, George TI, Nowels $\mathrm{KW}$, Birdwell SL, et al. New bilateral microcalcifications at mammography in a postlactational woman: case report. Radiology 2000;217:247-50.

24. Mercado CL, Koenigsberg TC, Hamele-Bena D, Smith SJ. Calcifications associated with lactational changes of the breast: mammographic findings with histologic correlation. AJR Am J Roentgenol 2002;179:685-9.

25. Giron GL, Boolbol SK, Gross J, Cohen JM, Feldman S. Postlactational microcalcifications. Breast J 2004; 10:247-52.

26. Lafreniere R. Bloody nipple discharge during pregnancy: a rationale for conservative treatment. J Surg Oncol 1990;43:228-30.

27. Kline TS, Lash SR. The bleeding nipple of pregnancy and postpartum period: a cytologic and histologic study. Acta Cytol 1964;8:336-40.

28. O'Callaghan MA. Atypical discharge from the breast during pregnancy and/or lactation. Aust N Z J Obstet Gynaecol 1981;21:214-6.

29. Scott-Conner CE. Diagnosing and managing breast disease during pregnancy and lactation. Medscape Womens Health 1997;2:1.

30. Rosen PP. Inflammatory and reactive tumors. In: Rosen PP, editor. Rosen's breast pathology. 2nd ed. Philadelphia (PA): Lippincott-Raven; 2001. p.29-63.

31. Gomez A, Mata JM, Donoso L, Rams A. Galactocele: three distinctive radiographic appearances. Radiology 1986; 158:43-4.

32. Sawhney S, Petkovska L, Ramadan S, Al-Muhtaseb S, Jain R, Sheikh M. Sonographic appearances of galactoceles. J Clin Ultrasound 2002;30:18-22.

33. Kim MJ, Kim EK, Park SY, Jung HK, Oh KK, Seok JY. Galactoceles mimicking suspicious solid masses on sonography. J Ultrasound Med 2006;25:145-51.

34. Stevens K, Burrell HC, Evans AJ, Sibbering DM. The ultrasound appearances of galactocoeles. Br J Radiol 1997;70:239-41.

35. Stafford I, Hernandez J, Laibl V, Sheffield J, Roberts S, Wendel G Jr. Community-acquired methicillin-resistant Staphylococcus aureus among patients with puerperal mastitis requiring hospitalization. Obstet Gynecol 2008;112:533-7. 


\section{Obstetrics \& Gynecology Science}

Vol. 56, No. 3, 2013

36. Marchant DJ. Inflammation of the breast. Obstet Gynecol Clin North Am 2002;29:89-102.

37. Dixey JJ, Shanson DC, Williams TD, Rustin MH, Crook SJ, Midgley J, et al. Toxic-shock syndrome: four cases in a London hospital. Br Med J (Clin Res Ed) 1982;285:342-3.

38. Karstrup S, Solvig J, Nolsoe CP, Nilsson P, Khattar S, Loren I, et al. Acute puerperal breast abscesses: US-guided drainage. Radiology 1993;188:807-9.

39. Ulitzsch D, Nyman MK, Carlson RA. Breast abscess in lactating women: US-guided treatment. Radiology 2004;232:904-9.

40. Eryilmaz R, Sahin M, Hakan Tekelioglu M, Daldal E. Management of lactational breast abscesses. Breast 2005;14:375-9.

41. Memis A, Bilgen I, Ustun EE, Ozdemir N, Erhan Y, Kapkac M. Granulomatous mastitis: imaging findings with histopathologic correlation. Clin Radiol 2002;57:1001-6.

42. Yilmaz E, Lebe B, Usal C, Balci P. Mammographic and sonographic findings in the diagnosis of idiopathic granulomatous mastitis. Eur Radiol 2001;11:2236-40.

43. Han BK, Choe YH, Park JM, Moon WK, Ko YH, Yang $J H$, et al. Granulomatous mastitis: mammographic and sonographic appearances. AJR Am J Roentgenol 1999;173:317-20.

44. Fletcher A, Magrath IM, Riddell RH, Talbot IC. Granulomatous mastitis: a report of seven cases. J Clin Pathol 1982;35:941-5.

45. Asoglu O, Ozmen V, Karanlik H, Tunaci M, Cabioglu $N$, Igci $A$, et al. Feasibility of surgical management in patients with granulomatous mastitis. Breast J 2005;11:108-14.

46. Tuncbilek N, Karakas HM, Okten OO. Imaging of granulomatous mastitis: assessment of three cases. Breast 2004; 13:510-4.

47. Lai EC, Chan WC, Ma TK, Tang AP, Poon CS, Leong HT. The role of conservative treatment in idiopathic granulomatous mastitis. Breast J 2005;11:454-6.

48. Rosen PP. Breast tumors in children. In: Rosen PP, editor. Rosen's breast pathology. Philadelphia (PA): LippincottRaven; 2001. p.729-48.

49. Dehner LP, Hill DA, Deschryver K. Pathology of the breast in children, adolescents, and young adults. Semin Diagn Pathol 1999;16:235-47.

50. Baker TP, Lenert JT, Parker J, Kemp B, Kushwaha A, Evans $\mathrm{G}$, et al. Lactating adenoma: a diagnosis of exclusion.
Breast J 2001;7:354-7.

51. Saglam A, Can B. Coexistence of lactating adenoma and invasive ductal adenocarcinoma of the breast in a pregnant woman. J Clin Pathol 2005;58:87-9.

52. Behrndt VS, Barbakoff D, Askin FB, Brem RF. Infarcted lactating adenoma presenting as a rapidly enlarging breast mass. AJR Am J Roentgenol 1999;173:933-5.

53. Sumkin JH, Perrone AM, Harris KM, Nath ME, Amortegui AJ, Weinstein BJ. Lactating adenoma: US features and literature review. Radiology 1998;206:271-4.

54. Yang WT, Suen M, Metreweli C. Lactating adenoma of the breast: antepartum and postpartum sonographic and color Doppler imaging appearances with histopathologic correlation. J Ultrasound Med 1997;16:145-7.

55. Darling ML, Smith DN, Rhei E, Denison CM, Lester SC, Meyer JE. Lactating adenoma: sonographic features. Breast J 2000;6:252-6.

56. Rosen PP. Fibroepithelial neoplasms. In: Rosen PP, editor. Rosen's breast pathology. 2nd ed. Philadelphia (PA): Lippincott-Raven; 2001. p.163-200.

57. O'Hara MF, Page DL. Adenomas of the breast and ectopic breast under lactational influences. Hum Pathol 1985;16:707-12.

58. Novotny DB, Maygarden SJ, Shermer RW, Frable WJ. Fine needle aspiration of benign and malignant breast masses associated with pregnancy. Acta Cytol 1991;35:676-86.

59. Raju GC, Naraynsingh V. Infarction of fibroadenoma of the breast. J R Coll Surg Edinb 1985;30:162-3.

60. Majmudar B, Rosales-Quintana S. Infarction of breast fibroadenomas during pregnancy. JAMA 1975;231:963-4.

61. Jimenez JF, Ryals RO, Cohen C. Spontaneous breast infarction associated with pregnancy presenting as a palpable mass. J Surg Oncol 1986;32:174-8.

62. Petrek JA, Theriault RL. Pregnancy-associated breast cancer and subsequent pregnancy in breast cancer survivors. In: Harris JR, Lippman ME, Morrow M, Osborne CK, editors. Diseases of the breast. 3rd ed. Philadelphia (PA): Lippincott Williams \& Williams; 2004. p.1035-46.

63. Ring $A E$, Smith IE, Ellis PA. Breast cancer and pregnancy. Ann Oncol 2005;16:1855-60.

64. Fuentes-Alburo A, Chavez-McGregor R, Ramirez Ugalde MT, De la Garza-Salazar JG. Early detection of breast cancer: who is responsible? 23rd Annual San Antonio Breast Cancer Symposium. Breast Cancer Res Treat 2000;64:250. 


\section{Obstetrics \& Gynecology Science}

Ji Hoon Yu, et al. Breast diseases in pregnancy \& lactation

65. Chiechi LM, Lobascio A, Loizzi P. Breast cancer in pregnancy. Resistance to screening. Minerva Ginecol 1998;50:301-4.

66. Nettleton J, Long J, Kuban D, Wu R, Shaefffer J, El-Mahdi A. Breast cancer during pregnancy: quantifying the risk of treatment delay. Obstet Gynecol 1996;87:414-8.

67. Johannsson O, Loman N, Borg A, Olsson H. Pregnancyassociated breast cancer in BRCA1 and BRCA2 germline mutation carriers. Lancet 1998;352:1359-60.

68. Jernstrom H, Lerman C, Ghadirian P, Lynch HT, Weber
B, Garber J, et al. Pregnancy and risk of early breast cancer in carriers of BRCA1 and BRCA2. Lancet 1999;354:1846-50.

69. Andrieu N, Goldgar DE, Easton DF, Rookus M, Brohet $R$, Antoniou AC, et al. Pregnancies, breast-feeding, and breast cancer risk in the International BRCA1/2 Carrier Cohort Study (IBCCS). J Natl Cancer Inst 2006;98:535-44. 70. Cullins SL, Pridjian G, Sutherland CM. Goldenhar's syndrome associated with tamoxifen given to the mother during gestation. JAMA 1994;271:1905-6. 